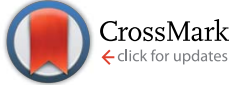

Cite this: RSC Adv., 2015, 5, 31049

\title{
Effective heterogeneous electro-Fenton process of $m$-cresol with iron loaded actived carbon
}

\author{
Loubna Bounab, ${ }^{\text {abc }}$ Olalla Iglesias, ${ }^{b}$ Elisa González-Romero, ${ }^{c}$ Marta Pazos ${ }^{\mathrm{b}}$ \\ and M. Ángeles Sanromán*b
}

The degradation of $m$-cresol (MC) has been investigated by a heterogeneous electro-Fenton process using iron loaded activated carbon (Fe-AC) as the heterogeneous electro-Fenton catalyst. Experimental results demonstrated that $M C$ was effectively removed through an electro-Fenton process. Calculated TOC removal and overall energy consumption showed that the use of a low iron concentration ( $28 \mathrm{mg} \mathrm{L}^{-1}$ ) increases the efficiency of the process. The reactions followed a pseudo-first order kinetic equation and kinetic coefficients confirm that the $M C$ reduction, when it is alone, is faster than in the presence of a similar compound, tert-butylhydroquinone (TBHQ) (from 0.0935 to $0.0692 \mathrm{~min}^{-1}$ ); therefore TBHQ exerts an antioxidative protection effect. In all cases, it is concluded that heterogeneous electro-Fenton treatment with Fe-AC follows a two-step process: adsorption and oxidation; allowing removal rates higher than in the literature. In addition, the reusability of this catalyst was demonstrated by operating it in continuous mode. Finally, LC-MS analysis allowed the development of a plausible degradation route.

Received 17th February 2015 Accepted 25th March 2015

DOI: 10.1039/c5ra03050a

www.rsc.org/advances
EAOP for the treatment of a wide variety of organic pollutants. ${ }^{15-19}$ The performance of this process is based on the electrochemical in situ generation of $\mathrm{H}_{2} \mathrm{O}_{2}$ from the continuous aeration on the cathode (eqn (1)). $\mathrm{Fe}^{2+}$ present on the media catalyst the in situ generation of highly oxidant hydroxyl radicals from $\mathrm{H}_{2} \mathrm{O}_{2}$ (eqn (2)), furthermore $\mathrm{Fe}^{2+}$ is continuously recycled by a direct cathodic reaction as shows eqn (3). The hydroxyl radicals produced are highly oxidative and non-selective molecules that degrade the organic matter. ${ }^{20-22}$

$$
\begin{gathered}
\mathrm{O}_{2}+2 \mathrm{H}^{+}+2 \mathrm{e}^{-} \rightarrow \mathrm{H}_{2} \mathrm{O}_{2} \\
\mathrm{H}_{2} \mathrm{O}_{2}+\mathrm{Fe}^{2+} \rightarrow \mathrm{HO}^{\cdot}+\mathrm{OH}^{-}+\mathrm{Fe}^{3+} \\
\mathrm{Fe}^{3+}+\mathrm{e}^{-} \rightarrow \mathrm{Fe}^{2+}
\end{gathered}
$$

A crucial parameter for ensuring the appropriate performance of the electro-Fenton process is the electrode material. Several articles reported the removal of $m$-cresol by electroFenton process using GDE, Ti/SnO ${ }_{2}-\mathrm{Sb}_{2} \mathrm{O}_{5}-\mathrm{IrO}_{2}$ and $\mathrm{PbO}_{2}$ electrodes. ${ }^{2,23}$ However, the last reports determined that borondoped diamond electrodes (BDD) are the most promising anode for EAOPs because they have significant characteristics, such as corrosion stability, low adsorption properties and great oxidizing power to remove organic pollutants. ${ }^{24-26}$ It can be ascribed to its high $\mathrm{O}_{2}$-overpotential, which allows the generation of high yields of the strong oxidant hydroxyl radical (BDD-HO') adsorbed on its surface from water oxidation (eqn (4)). ${ }^{25,27,28}$

$$
\mathrm{BDD}\left(\mathrm{H}_{2} \mathrm{O}\right) \rightarrow \mathrm{BDD}-\mathrm{HO}^{\cdot}+\mathrm{H}^{+}+\mathrm{e}^{-}
$$


Cathode material should optimize the generation of $\mathrm{H}_{2} \mathrm{O}_{2}$ among other reduction reactions. Among the different materials that can be used as cathode, foam materials have higher reaction surface, thus the use of nickel foam as cathode can improve the production of hydroxyl radicals; furthermore the presence of nickel produces an additional $\mathrm{H}_{2} \mathrm{O}_{2}$ generation from the superoxide radical (eqn (5) and (6)). ${ }^{29}$

$$
\begin{aligned}
& \mathrm{Ni}+2 \mathrm{O}_{2} \rightarrow \mathrm{Ni}^{2+}+2 \cdot \mathrm{O}_{2}^{-} \\
& \mathrm{O}_{2}{ }^{-}+\mathrm{e}^{-}+2 \mathrm{H}^{+} \rightarrow \mathrm{H}_{2} \mathrm{O}_{2}
\end{aligned}
$$

Industrial activities constantly produce wastewaters that need a treatment. Therefore, it is necessary to validate an adequate technique to continuously remediate polluted streams. In the electro-Fenton process iron on solution gets away on the outflow. Therefore, it is further necessary to improve the electro-Fenton technology in order to reduce this problem and reduce the investment and operation costs. Several studies have focused on the immobilization of iron on supports with physical characteristics that avoid its lost. ${ }^{\mathbf{1 5 , 3 0}}$ Activated carbon (AC) is characterized by its great absorption capacity and it has already been used as iron support with different environmental applications. ${ }^{31-33}$ In order to overcome the main drawback of the electro-Fenton process operating in continuous mode in this study the use of iron loaded in $\mathrm{AC}$ (FeAC) is considered a workable solution.

The aim of this work is to design an electro-Fenton continuous reactor with BDD as anode and nickel foam as cathode to treat polluted effluents in a continuous mode at the bench scale using Fe-AC as Fenton catalyst. To analyse the technique's capacity, $m$-cresol and tert-butylhydroquinone were used as model pollutants.

\section{Experimental}

\section{Materials}

In this study, solutions of $m$-cresol (MC) $\left(100 \mathrm{mg} \mathrm{L}^{-1}\right)$ and tertbutylhydroquinone (TBHQ) were provided by Sigma-Aldrich
(Barcelona, Spain) and used in order to evaluate the electroFenton treatments. Their structure and properties are shown in Table 1.

\section{Catalyst preparation and characterization}

Iron load on activated carbon (Fe-AC) was carried out by mixing a constant volume $(0.15 \mathrm{~L})$ of iron aqueous solution at $1000 \mathrm{mg} \mathrm{L}^{-1}$ of $\mathrm{Fe}^{3+}\left(\mathrm{Fe}_{2} \mathrm{SO}_{3}\right.$; Sigma-Aldrich, Spain) with $3 \mathrm{~g}$ of activated carbon (AC) (Granulated $\mathrm{n}^{\circ} 2$ QP Panreac Spain) in $0.25 \mathrm{~L}$ Erlenmeyer flasks. The flasks were agitated in an incubator (Thermo Forma 420) at $150 \mathrm{rpm}$ and $20{ }^{\circ} \mathrm{C}$ for 30 minutes. The phenantroline method 3500 D (Standard Methods-18 Ed. 1992) was used to measure the iron that remained unabsorbed in the supernatant liquid. Finally, the resulting Fe-AC composite was dried in an oven at $105{ }^{\circ} \mathrm{C}$ and stored at room temperature.

Fe-AC was characterized by Scanning Electron Microscopy (SEM) performed on a JEOL JSM-6700F equipped with an Energy Dispersive Microanalysis (EDS) Oxford Inca Energy 300 SEM using an accelerating voltage of $20 \mathrm{kV}$ (Electron Microscopy Service, C.A.C.T.I., University of Vigo).

\section{Electro-Fenton reactor set-up}

The heterogeneous electro-Fenton with Fe-AC was performed in a cylindrical glass reactor with a working volume of $0.15 \mathrm{~L}$. The electric field ( $5 \mathrm{~V}$ ) was applied by a $1.6 \mathrm{~mm}$ thick nickel foam cathode (Goodfellow Cambridge Ltd, United Kingdom) and a BDD anode (DIACHEM ${ }^{\circledR}$, Germany) connected to a direct current power supply (HP model 3662, Agilent Technologies Spain, S.L.). The electrodes (surface $15 \mathrm{~cm}^{2}$ ) were placed opposite to each other at $1 \mathrm{~cm}$ above the bottom of the cell and with an electrode gap of $6 \mathrm{~cm}$. Current intensity was monitored with a multimeter (Fluke 175). $\mathrm{H}_{2} \mathrm{O}_{2}$ was continuously electrogenerated via oxygen reduction on the cathode, by bubbling $1 \mathrm{~L} \mathrm{~min}^{-1}$ of compressed air. Reaction mixture contains $150 \mathrm{~mL}$ of solution $\mathrm{Na}_{2} \mathrm{SO}_{4}(0.01 \mathrm{M})$ as electrolyte, $100 \mathrm{mg} \mathrm{\textrm {L } ^ { - 1 }}$ of phenolic compound and $3 \mathrm{~g}$ of $\mathrm{Fe}-\mathrm{AC}$ at different iron concentrations (46 $\mathrm{mg} \mathrm{L}^{-1}$ and $28 \mathrm{mg} \mathrm{L}^{-1}$ ). The $\mathrm{pH}$ was adjusted to 2 by the addition of sulphuric acid (Sigma Aldrich, Spain). The medium

Table 1 Chemical formula and structure, CAS number and concentration of studied compounds

\begin{tabular}{lcl}
\hline Compound & $\mathrm{CAS}$ number & $\begin{array}{c}\text { Molecular } \\
\text { formula }\end{array}$ \\
\hline -Cresol (MC) & $108-39-4$ & $\begin{array}{c}\text { Concentration } \\
\left(\mathrm{mg} \mathrm{L}^{-1}\right)\end{array}$ \\
tert-Butylhydroquinone (TBHQ) & $1948-33-0$ &
\end{tabular}


was maintained in suspension by magnetic stirring avoiding concentration gradients in the cell.

\section{Sample preparation and preservation}

For all experiments, $1 \mathrm{~mL}$ samples were taken periodically from the reactor, centrifuged (Sigma 3K-18) for 10 minutes at $7000 \mathrm{rpm}$ to remove solid and stored at $4{ }^{\circ} \mathrm{C}$ until chemical analysis.

\section{Analytical procedures}

A survey of literature describes the analytical methods available for quantifying, monitoring and detecting phenolic compounds. $^{34}$ In this work, HPLC, LC-MS and TOC analysis were performed.

The concentrations of MC and TBHQ were quantified by means of HPLC (Agilent 1100) equipment with an XDF-C8 reverse-phase column $(150 \times 4.6 \mathrm{~mm}$ i.d., $5 \mu \mathrm{m})$. Prior to injection, the samples were filtered through a $0.45 \mu \mathrm{m}$ Teflon filter. The injection volume was set at $10 \mu \mathrm{L}$, and the gradient of eluent (acetonitrile/water with a $1.5 \%$ of acetic acid) was pumped at a rate of $1 \mathrm{~mL} \min ^{-1}$ for 20 minutes. Detection was performed with a diode array detector at $274 \mathrm{~nm}$ for MC and $292 \mathrm{~nm}$ for TBHQ, and the column was maintained at room temperature.

In order to identify the transformation products obtained in the MC degradation several samples were analyzed with an LC-MS (Agilent 1100) equipment with a LC column ZORBAX. Filtration through a $0.45 \mu \mathrm{m}$ Teflon filter was done before the injection. In this case the isocratic eluent was 90 (water) : 10 (acetonitrile) that was pumped at a rate of $0.5 \mathrm{~mL} \min ^{-1}$ for 40 minutes. Detection was carried out with a diode array detector at $218 \mathrm{~nm}$ and the column temperature was maintained at $23^{\circ} \mathrm{C}$. The coupled mass spectrometer employed was a HewlettPackard 5989B with a detection range from 10 to 2000 Da.

Total organic carbon (TOC) in aqueous solutions was determined by using a Lange curette test (LCK 380) in a Hach Lange DR 2800, according to stand method DIN 38409-H3. The sample was introduced in the Lange cuvette. Under the conditions of the test, the carbon forms carbon dioxide, which diffuses through a membrane into an indicator solution. The change of color of the indicator solution is evaluated photometrically.

$\mathrm{H}_{2} \mathrm{O}_{2}$ concentration was determined by the titanium oxalate method..$^{35}$ The method is based on the generation of a yelloworange titanium(Iv) peroxide complex with a maximum absorbance at $400 \mathrm{~nm}$. Thus, $2 \mathrm{~mL}$ of sample are mixed with $0.25 \mathrm{~mL}$ of sulphuric acid $\left(0.5 \mathrm{mmol} \mathrm{L}^{-1}\right), 0.2 \mathrm{~mL}$ of potassium titanium oxide oxalate dehydrate $\left(0.14 \mathrm{~mol} \mathrm{~L}^{-1}\right)$ and $0.05 \mathrm{~mL}$ of distilled water for a final volume of $2.5 \mathrm{~mL}$, after 5 minutes the absorbance was measured spectrophotometrically. All reagents were provided by Sigma-Aldrich (Barcelona, Spain).

\section{Kinetic studies}

Kinetic studies were done in order to model the behavior of the heterogeneous EF-Fe-AC. The concentration profiles of selected degradation compounds were fitted by a suitable kinetic equation and the rate constants were calculated by using SigmaPlot 4.00 (1997) software. The SigmaPlot curve fitter uses an iterative

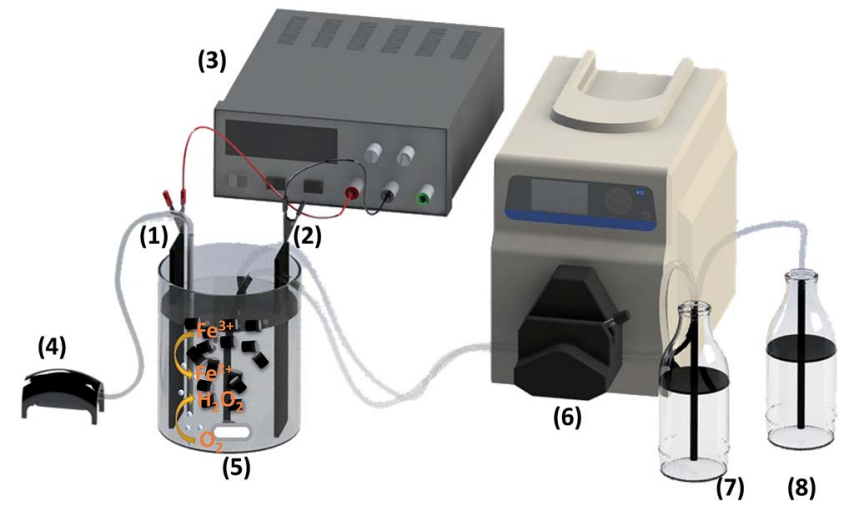

Fig. 1 Schematic diagram of electro-Fenton experimental set-up in continuous processing: (1) nickel foam acting as cathode, (2) BDD electrode acting as anode, (3) powersupply, (4) air supply, (5) magnetic stirrer, (6) dual-headed peristaltic pump, (7) inlet flow, (8) outlet flow.

procedure, based on the Marquardt-Levenberg algorithm, which seeks the values of the parameters that minimize the sum of the squared differences between the observed and predicted values of the dependent variable.

\section{Measurement of process efficiency}

In addition to analyzing compounds concentration and therefore their removal during the experiments, other specific energetic parameter is useful such as energy consumption per amount of TOC destroyed (eqn (7)) were evaluated.

$$
\text { Energy consumption }\left(\mathrm{kW} \mathrm{h} \text { per } \mathrm{kg}_{\mathrm{TOC}}\right)=\frac{I V t}{\left(\Delta m_{\mathrm{TOC}}\right) V_{\mathrm{s}}}
$$

where $I$ is the average applied current (A), $V$ is the cell voltage $(\mathrm{V}), t$ is the treatment time $(\mathrm{h}), V_{\mathrm{s}}$ is the solution volume (L) and $\Delta m_{\text {TOC }}$ is the decay in TOC concentration $\left(\mathrm{g} \mathrm{L}^{-1}\right)$.

\section{Continuous EF-FeAC process set-up}

An electrochemical cell with the same characteristics than the one used for the batch experiments was selected (Fig. 1). The electro-Fenton reactor had a working volume of $0.15 \mathrm{~L}$ with $3 \mathrm{~g}$ of FeAC at an iron concentration of $28 \mathrm{mg} \mathrm{L}^{-1}$ and $\mathrm{pH} 2 . \mathrm{H}_{2} \mathrm{O}_{2}$ was produced electrochemically by bubbling compressed air near the cathode at approximately $1 \mathrm{~L} \mathrm{~min}^{-1}$. The polluted solution was homogenized by a magnetic stirrer. A dual-headed peristaltic pump was used to maintain a continuous flow of MC solution through the reactor. Samples from the outlet flow were frequently taken to measure $\mathrm{pH}$ and analyze $\mathrm{MC}$ concentration. The reactor operated in continuous mode at residence times of 45 and 60 minutes. In all cases, each steady-state was maintained for at least three times the residence time.

\section{Results and discussion}

\section{Heterogeneous electro-Fenton treatment of MC}

Initially, the preparation of Fe-AC was carried out by adsorption technique. Due to precipitation of the $\mathrm{Fe}^{3+}$ as iron hydroxide, it is not possible to carry out adsorption experiments with iron at 
$\mathrm{pH}>4$.0. For this reason, in these experiments, the natural $\mathrm{pH}$ of the iron solution was used. The kinetic of iron adsorption can provide valuable insights about the reaction pathways and mechanisms of the reaction. The kinetic and thermodynamic behaviour of the adsorption reaction fitted very well to a pseudosecond-order model and the adsorption is endothermic in nature and mainly physical. ${ }^{36-38}$

In order to verify the adsorption of iron onto AC a Scanning Electron Microscopy and Energy Dispersive Spectrometry (SEM/EDS) was performed. EDS is an analytical technique used for the elemental analysis or chemical characterization of a sample. As can be seen in the SEM images (Fig. 2), AC has high porosity and consequently a good adsorption capacity. In addition, EDS spectral analysis confirms the increasing of iron onto the Fe-AC after the adsorption process. The elementary composition of the AC indicates that there is not iron with a carbon content of $89.19 \%$, however this value change after the adsorption and the composition of Fe-AC is $84.61 \%$ of carbon and the iron concentration increased up to $2.53 \%$. These results reflected that iron specie remained homogeneously onto the AC structure (Fig. 2B).

The electro-Fenton process with Fe-AC was conducted in batch mode with two initial iron concentrations $46 \mathrm{mg} \mathrm{L}^{-1}$ and $28 \mathrm{mg} \mathrm{L}^{-1}$ on Fe-AC. Fig. 3 shows the profile of MC reduction along the treatment time. As can be observed, the heterogeneous electro-Fenton with a lower iron concentration on Fe-AC improves the rate of MC reduction. Thus, it was determined that the best iron concentration is $28 \mathrm{mg} \mathrm{L}^{-1}$ in order to carry out the electro-Fenton reactions with Fe-AC for the treatment of MC. This result is in agreement with several other studies such as the cresol degradation by Fenton process and phenol degradation by electro-Fenton and sonoelectro-Fenton processes. ${ }^{\mathbf{1 , 3 9}}$ In these studies, it was reported that a further increase in $\mathrm{Fe}^{2+}$ ion concentration did not correspondingly increase its reactivity, probably due to direct reaction of hydroxyl radical with metal ions. In addition, our results are in concordance with other previous results in which it is postulated that AC is able to decompose hydrogen peroxide and, therefore, to generate hydroxyl radical. For this reason, it the presence of a high iron concentration into AC is not necessary. ${ }^{40}$

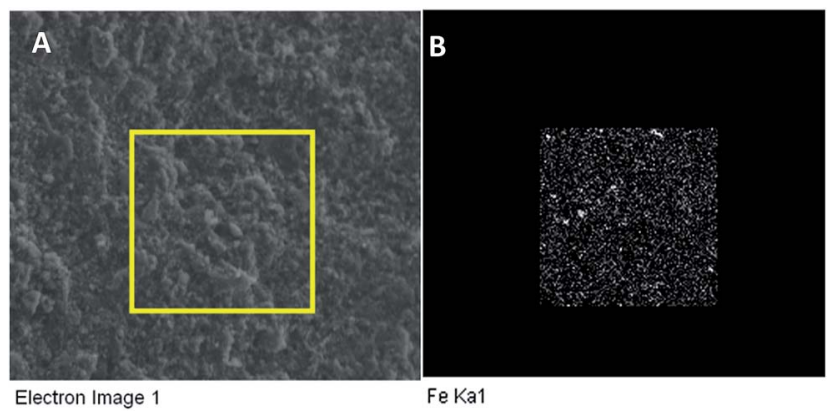

Fig. 2 (A) Scanning electron microscopy (SEM) image of Fe-AC and (B) Fe mapping of energy dispersive scanning spectroscopy (EDS) of Fe-AC.

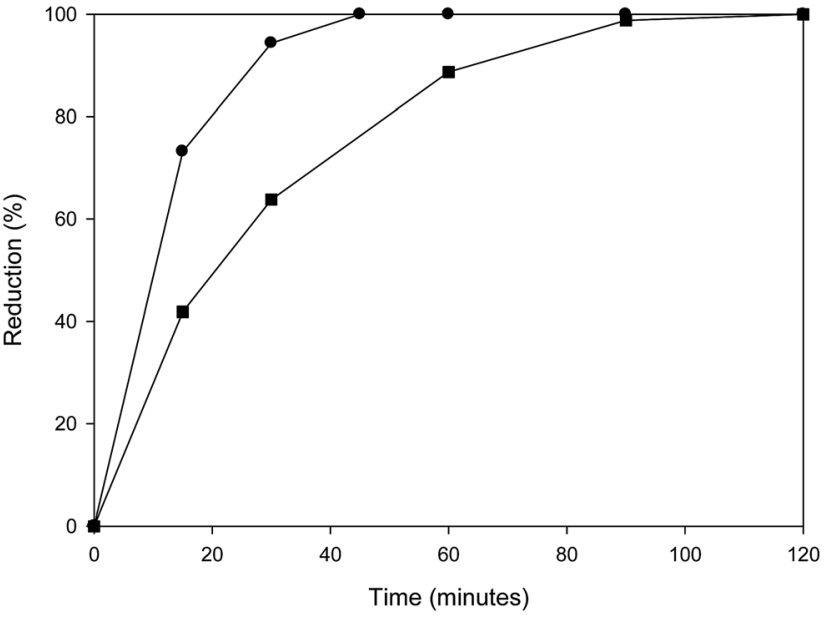

Fig. 3 Profiles of $M C$ reduction by heterogeneous electro-Fenton with $\mathrm{Fe}-\mathrm{AC}$ at an iron concentration of $46 \mathrm{mg} \mathrm{L}^{-1}$ (black squares) and $28 \mathrm{mg} \mathrm{L}^{-1}$ (black circles).

In this experiments the $\mathrm{H}_{2} \mathrm{O}_{2}$ was generated and transformed in Fenton's reactions and the $\mathrm{H}_{2} \mathrm{O}_{2}$ concentration was around $0.3-0.4 \mathrm{mmol} \mathrm{L}^{-1}$. This fact is due to air and nickel react to generate $\mathrm{H}_{2} \mathrm{O}_{2}$ as described in eqn (5) and (6), this results are in accordance with those obtained by $\mathrm{Liu}^{29}$ who reported the improvement on the $\mathrm{H}_{2} \mathrm{O}_{2}$ generation and consequently the hydroxyl radical generation. Moreover, the regeneration of $\mathrm{Ni}^{2+}$ due to the electric field avoids the nickel ions leaching and the electrode keeps its structure and composition along the treatment.

The MC concentration profiles allow the evaluation of the kinetic behavior of this reaction. The obtained data were adjusted to several orders and the best fit was obtained when a pseudo-first-order kinetic expression was used (eqn (8)).

$$
\frac{\mathrm{d} C}{\mathrm{~d} t}=-k C
$$

where $C$ is concentration of $\mathrm{MC}\left(\mathrm{mg} \mathrm{L}^{-1}\right) ; t$ is reaction time (min) and $k$ is kinetic coefficient for the pseudo-first order reaction $\left(\mathrm{min}^{-1}\right)$.

This result is in accordance with the postulated by Lucas \& Peres $^{\mathbf{4 1}}$ for the Fenton treatment of olive mill wastewater and the electro-Fenton treatment of MC. They concluded that the reaction kinetic behaviour could be represented by a simple irreversible reaction of pseudo-first-order kinetics with respect to MC concentration. This behaviour was also corroborated by Chu. ${ }^{42}$

The rate constants values and the statistical correlation parameters are shown in Fig. 4. As expected from the degradation profiles, the highest kinetic parameter value was $k=0.0935 \mathrm{~min}^{-1}$ to the lower iron concentration $\left(28 \mathrm{mg} \mathrm{L}^{-1}\right) . \mathrm{Chu}^{42}$ surveyed the effect of iron and initial MC concentration on the decay kinetics of electrochemical degradation of $\mathrm{MC}$ using porous carbonnanotube-containing cathode and $\mathrm{Ti} / \mathrm{SnO}_{2}-\mathrm{Sb}_{2} \mathrm{O}_{5}-\mathrm{IrO}_{2}$ anode. They observed that the kinetic parameter value $\left(0.0239 \mathrm{~min}^{-1}\right)$ obtained with $33.6 \mathrm{mg} \mathrm{L}^{-1}$ of iron was evidently lower than the value $\left(0.0276 \mathrm{~min}^{-1}\right)$ obtained at an iron concentration of 


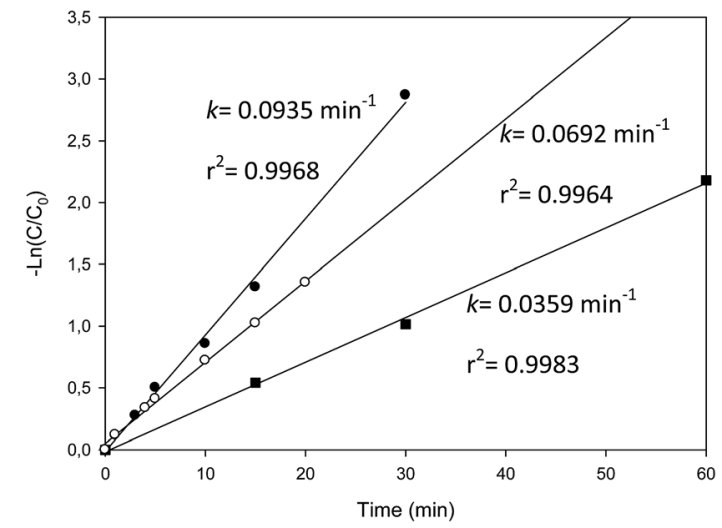

Fig. 4 Pseudo-first-order kinetic equation of heterogeneous electroFenton of $M C$ (black circles) working with $28 \mathrm{mg} \mathrm{L}^{-1}$ of iron, $M C$ in presence of TBHQ (white circles) working with $28 \mathrm{mg} \mathrm{L}^{-1}$ of iron and $\mathrm{MC}$ (black squares) working with $46 \mathrm{mg} \mathrm{L}^{-1}$ of iron.

$22.4 \mathrm{mg} \mathrm{L}{ }^{-1}$. Although the effect of iron was similar, the kinetic values and the reaction rate were higher around 4-fold than reported in the literature. ${ }^{37}$

This fact could be due to the use of this catalyst Fe-AC. It is known that AC has a high adsorption capacity, which has been widely studied for the treatment of different polluted wastewaters. ${ }^{\mathbf{3 1 4 3 , 4 4}}$ Detailed explanation of the application of $\mathrm{AC}$ to phenolic adsorption has been given by Busca. ${ }^{45}$ As it is mentioned in previous papers the heterogeneous electroFenton treatment is a process that takes place in two steps. ${ }^{15,46}$ Initially, the pollutant is adsorbed on the catalyst and after it is degraded by oxidation reactions.

For testing this hypothesis, the adsorption on Fe-AC of MC and MC desorption after electro-Fenton treatment was evaluated. As it can be seen in Fig. 5 a high adsorption rate was detected, reaching a total MC reduction by adsorption after 120 minutes. However, in the heterogeneous electro-Fenton process, near complete reduction is achieved after 45 minutes (Fig. 3). Fe-AC proved to have a very high adsorption capacity

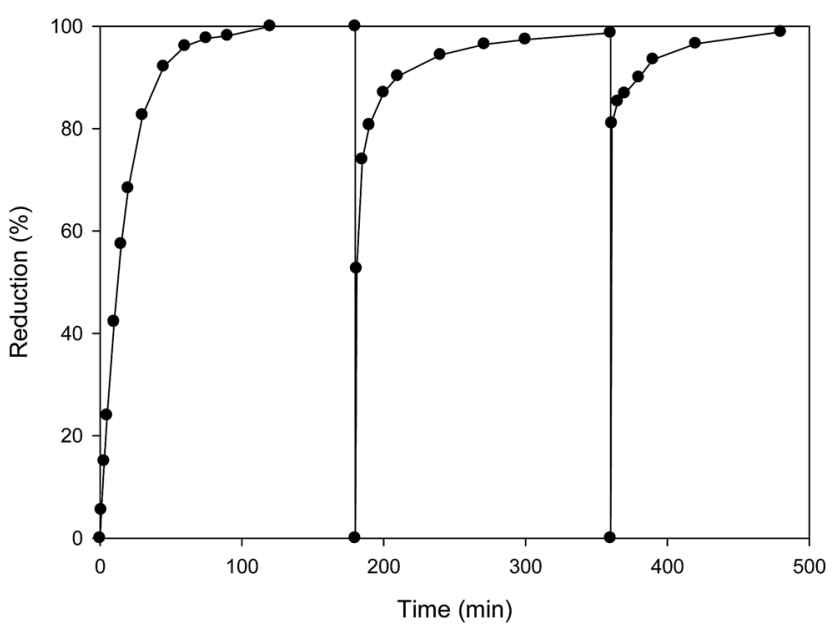

Fig. 5 Batch adsorption profiles of $\mathrm{MC}$ on Fe-AC. Each batch con-

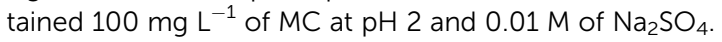

that did not reach the saturation after 3 cycles of $0.15 \mathrm{~L}$ of $\mathrm{MC}$ solution on $3 \mathrm{~g}$ of $\mathrm{Fe}-\mathrm{AC}$ at an iron concentration of $28 \mathrm{mg} \mathrm{L}^{-1}$.

Thus, these results indicate that the electro-Fenton of $\mathrm{MC}$ in heterogeneous electro-Fenton with $\mathrm{Fe}-\mathrm{AC}$ is a process that couples adsorption and degradation, for this reason after 90 minutes of electro-Fenton treatment, the remaining MC adsorbed on the Fe-AC is nearly the $1 \%$ of initial concentration. This results prove that adsorption on Fe-AC is followed by a fast degradation on the Fe-AC surface.

The TOC measurements show a similar behaviour as the MC reduction, thought they need more treatment time to reach the complete mineralization. Thus, after 120 minutes of treatment, TOC was reduced by $67.3 \%$ with $46 \mathrm{mg} \mathrm{L}^{-1}$ of iron and $83 \%$ with $28 \mathrm{mg} \mathrm{L}^{-1}$ of iron and the energy consumption per TOC reduced was 29.7 and $15.1 \mathrm{~kW} \mathrm{~h}$ per $\mathrm{kg}_{\text {TOC }}$ operating with initial iron concentrations of $46 \mathrm{mg} \mathrm{L}^{-1}$ and $28 \mathrm{mg} \mathrm{L}^{-1}$, respectively. This study has shown that the energy consumption from the system operating at the lower iron concentration was about 2 folds of magnitude lower than those obtained at initial iron concentrations of $46 \mathrm{mg} \mathrm{L}^{-1}$.

These TOC values were greater to that found by IsarainChávez ${ }^{47}$ for mineralization of organic pollutants by combined electrocoagulation and photoelectro-Fenton processes $(70 \%$ in 180 minutes) and $\mathrm{Liu}^{48}$ in the catalytic wet peroxide oxidation of MC; in which the TOC removal reached 51.0\% after 120 minutes of treatment. These results demonstrate the efficiency of the heterogeneous electro-Fenton with Fe-AC, which quantitatively reduces the organic load.

\section{Heterogeneous electro-Fenton treatment of TBHQ alone and in combination of $\mathrm{MC}$}

TBHQ is an antioxidant used on biodiesel to prevent its spoiling. ${ }^{49}$ This molecule was selected to evaluate its effect on the treatment of MC due to its similar structure and composition. For this reason, the electro-Fenton process was carried out at the optimal conditions $\left(\mathrm{pH} 2,0.01 \mathrm{M}\right.$ of $\mathrm{Na}_{2} \mathrm{SO}_{4}$ and $28 \mathrm{mg} \mathrm{\textrm {L } ^ { - 1 }}$ of iron concentration) to degrade a TBHQ solution and its combination with MC (Fig. 6).

Fig. 6 shows that the reduction of $\mathrm{MC}$ when TBHQ is present on the solution is lower than alone. In all cases, TBHQ is reduced faster than MC. The reduction of TBHQ is so fast that it is not modified in presence of MC. The kinetic study of the different treatments shows a pseudo-first order and the values of their kinetic coefficient confirm the aforementioned tendency, with a faster reduction of MC, when it is alone, than in presence of TBHQ (from 0.0935 to $0.0692 \mathrm{~min}^{-1}$ ) (Fig. 4). Therefore TBHQ seem to have an antioxidative protection of MC reducing its decomposition.

In addition, the adsorption of TBHQ on Fe-AC was studied. A faster adsorption is detected and all TBHQ is removed from the solution after 30 minutes; however in the electro-Fenton treatment the total reduction was achieved after 20 minutes. Furthermore, after a heterogeneous electro-Fenton with Fe-AC of TBHQ there is not TBHQ adsorbed on Fe-AC, which confirms the efficiency of the treatment. This fact confirms 


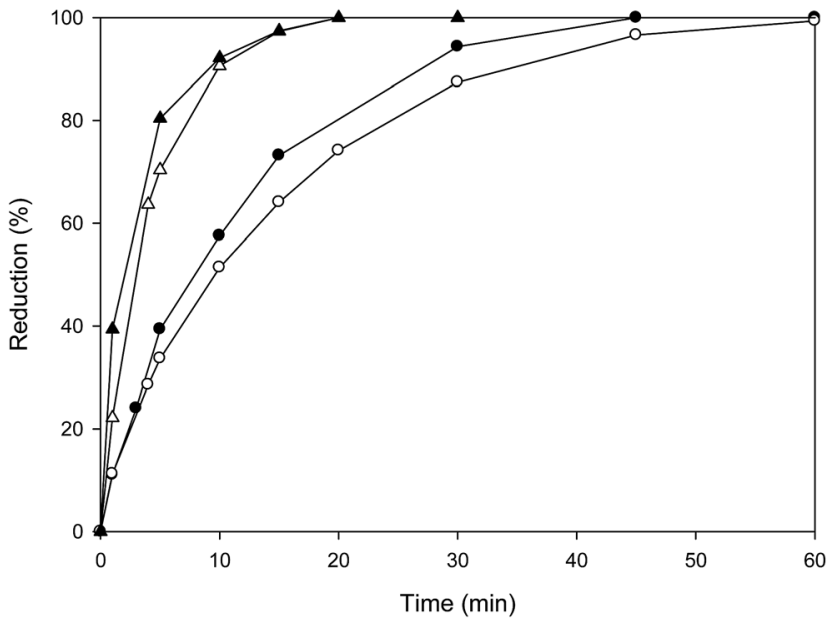

Fig. 6 Profiles of $\mathrm{MC}$ and $\mathrm{TBHQ}$ reduction by heterogeneous electroFenton with $\mathrm{Fe}-\mathrm{AC}$ at an iron concentration of $28 \mathrm{mg} \mathrm{L}^{-1}$ in different reaction media: $M C$ alone (black circles), $M C$ in presence of $\mathrm{TBHQ}$ (white circles), TBHQ alone (black triangles) and TBHQ in presence of $M C$ (white triangles).

again the hypothesis of a combined process with adsorption in catalyst followed by the degradation action of hydroxyl radical.

To verify the efficiency in the organic pollutant degradation by heterogeneous electro-Fenton with Fe-AC, the reduction in TOC was evaluated in all reaction media employed. TOC was not significantly influenced by the presence of several compounds in the reaction media. High TOC reduction $91.2 \%$ and $91.3 \%$ was detected after 120 minutes treatment of TBHQ alone and in combination of MC, respectively. This values are higher than found in the literature. Izaoumen ${ }^{50}$ studied the degradation of $o$-cresol and $p$-cresol by Fenton and photo-Fenton. They found that photo-Fenton process was more efficient than Fenton in the mineralization and $90 \%$ of TOC removal was achieved in 150 minutes of UV.

\section{Continuous heterogeneous electro-Fenton treatment of MC}

In order to evaluate the activity and stability of the catalytic action of the Fe-AC and minimize site requirements for the treatment of large amounts of wastewater, a continuous mode for the electro-Fenton with Fe-AC of MC at different residence times was tested. The process took place in a reactor of similar characteristics than the one used for batch experiments and described in experimental and Fig. 1. Initially the hydrodynamic behaviour of this reactor was studied through the residence time distribution (RTD) curves. These tracer experiments were carried out at different flow rates to confirm that the reactor used in this work closely matches ideal mixing conditions. Thus, the reactor behaved as a continuous stirred-tank reactor (CSTR) and it can be assumed that the concentration everywhere in the reactor is equal to the outlet concentration and the fluid has a mean residence time equal to the reactor volume divided by the volumetric flow rate through the tank.

To model this process it is necessary to include the kinetic behaviour determined in the previous batch experiments. An expression that relates the reduction of $\mathrm{MC}$ and residence times was obtained on the basis of the CSTR hydrodynamic behaviour and the first order kinetic model. It is shown in eqn (9).

$$
R=100 \frac{k \tau}{1+k \tau}
$$

where $R$ is the percentage of MC reduction, $k$ is the previously obtained kinetic coefficient for the first order reaction $\left(\mathrm{min}^{-1}\right)$ and $\tau$ is the residence time ( $\mathrm{min}$ ).

Fig. 7 shows the increase of reduction percentage with the residence time, attaining $72 \%$ for a residence time of 45 minutes and $80 \%$ for a residence time of 1 hour. The value of energy consumption per TOC reduced was found to be $8.2 \mathrm{~kW} \mathrm{~h}$ per $\mathrm{kg}_{\text {TOC }}$ and corresponding to TOC removal efficiency of $83.4 \%$, demonstrating adequate low energy consumptions.

In addition, the theoretical reduction values were calculated using eqn (9) for the two employed residence times, and they are represented in Fig. 7 as the long dashed line. The proposed model was able to satisfactorily describe the $\mathrm{MC}$ reduction data and to serve our goal of properly characterizing the kinetics of the remediation process.

\section{Analysis of MC degradation compounds}

In order to identify the transformation products obtained in the MC degradation, several samples were analyzed with LC-MS. The LC-MS study of MC solution treated in the heterogeneous electro-Fenton with Fe-AC was carried out at initial time, after 3 hours and after 24 hours.

At initial time several compounds with a phenolic group are found, while its intensity is very low and increases with treatment time. MC is only found at initial time, after 3 hours of treatment there are intermediate products that were identified and after 24 hours just a few compounds are found and identified. Among the phenolic derivatives found, 2-methylhydroquinone appears at initial degradation times and 2-methyl$p$-benzoquinone appears after 3 hours; however none of them appear after 24 hours of treatment time. These compounds were detected by Flox, ${ }^{2}$ Flox ${ }^{12}$ and $\mathrm{Chu}^{42}$ as intermediate products in

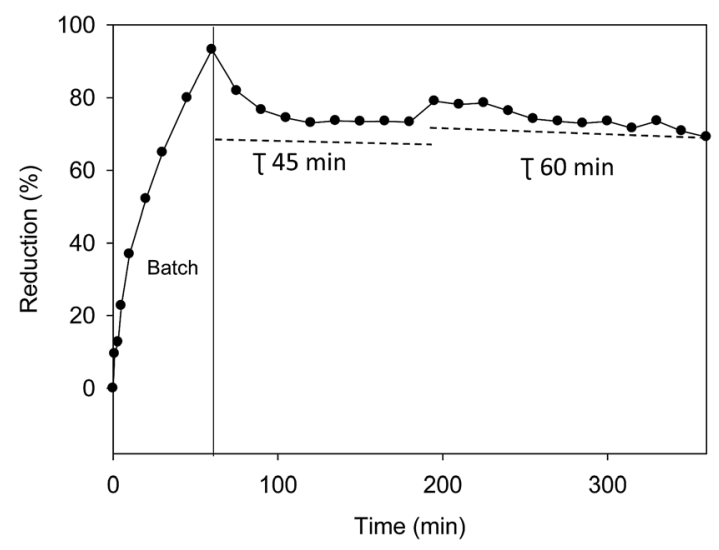

Fig. 7 Continuous electro-Fenton with Fe-AC $\left(28 \mathrm{mg} \mathrm{L}^{-1}\right)$ treatment of $\mathrm{MC}$ at two residence times ( 45 and $60 \mathrm{~min}$ ); dotted lines correspond with the theoretic reduction from the kinetic behaviour. 


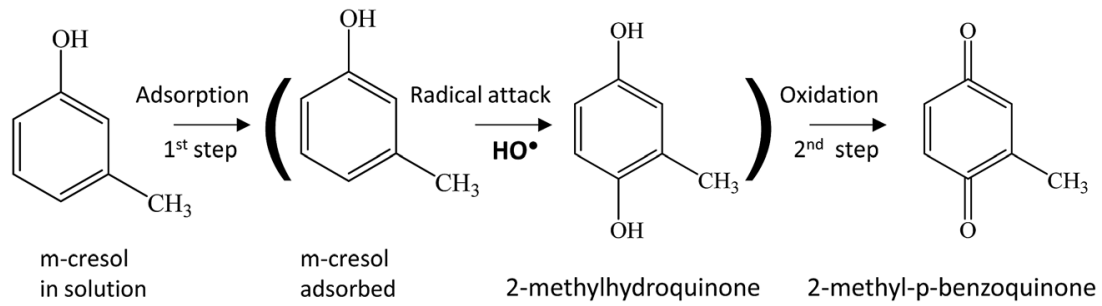

Fig. 8 Proposed reaction sequence on the degradation of $m$-cresol by the heterogeneous electro-Fenton with Fe-AC.

different EAOPs of MC. The degradation pathway is represented in Fig. 8. Similar reaction sequence for the electro-Fenton degradations of MC in acid medium using a BDD anode was proposed by Flox. ${ }^{12}$

\section{Conclusion}

In the present work, the heterogeneous electro-Fenton process used Fe-AC as catalyst for the degradation of MC. The performance of this technique is characterized by the following:

- AC demonstrated its capacity to absorb iron and to perform as catalyst on the heterogeneous electro-Fenton treatment.

- The evaluation of iron dosage showed that $28 \mathrm{mg} \mathrm{L}^{-1}$ contains the required amount to the electro-Fenton reactions to take place, besides AC has been found in literature as competitor on the hydroxyl radical production.

- The heterogeneous electro-Fenton treatment with Fe-AC has proved to be a process where adsorption is followed by oxidation leading a decontaminated wastewater and a pollutant free catalyst.

- The analysis of antioxidant TBHQ showed the capacity of this compound to slow down the MC degradation.

- Kinetic studies demonstrated that the process follows a pseudo-first-order kinetic equation which shows that $28 \mathrm{mg} \mathrm{L}^{-1}$ of iron behaves faster that $46 \mathrm{mg} \mathrm{L}^{-1}$ and that the presence of TBHQ diminishes the kinetic constant.

- The study of energy consumption and TOC removal further confirmed the efficiency of the developed process to the degradation of MC.

- The identification of a plausible degradation route eases the understanding of process oxidation pathways.

\section{Acknowledgements}

This research has been financially supported by the Spanish Ministry of Economy and Competitiveness, Xunta de Galicia and ERDF Funds (Projects CTM2011-26423, CTQ2011-28157, GRC 2013/003 and R2014/030). The authors are grateful to the Spanish Ministry of Economy and Competitiveness for financial support of the researcher Marta Pazos under a Ramón y Cajal program and Erasmus Mundus Green IT Program from EACEAEuropean Union (REF: 2012-2625/001-001-EM-Action2Partnerships-Staff mobility 2014) for research stay of Loubna Bounab.

\section{References}

1 V. Kavitha and K. Palanivelu, Water Res., 2005, 39, 30623072 .

2 C. Flox, P. Cabot, F. Centellas, J. A. Garrido, R. M. Rodríguez, C. Arias and E. Brillas, Appl. Catal., B, 2007, 75, 17-28.

3 United State Environmental Protection Agency, $m$-Cresol and xylenol, EPA 738-F-94-022, 1994.

4 CARB. California Air Resources Board, 2000.

5 Y. Ren, L. Peng, G. Zhao and C. Wei, Biochem. Eng. J., 2014, 88, 108-114.

6 S. Dey and S. Mukherjee, J. Environ. Sci., 2013, 25, 698-709.

7 L. Wang, Y. Yao, Z. Zhang, L. Sun, W. Lu, W. Chen and H. Chen, Chem. Eng. J., 2014, 251, 348-354.

8 L. T. Markovska, V. D. Meshko and M. S. Marinkovski, J. Serb. Chem. Soc., 2006, 71, 957-967.

9 M. Choquette-Labbé, W. A. Shewa, J. A. Lalman and S. R. Shanmugam, Water, 2014, 6, 1785-1806.

10 S. Adishkumar and S. Kanmani, Desalin. Water Treat., 2010, 24, 67-73.

11 Y. Zheng, D. O. Hill and C. H. Kuo, J. Hazard. Mater., 1993, 34, 245-260.

12 C. Flox, C. Arias, E. Brillas, A. Savall and K. Groenen-Serrano, Chemosphere, 2009, 74, 1340-1347.

13 M. Umar, H. A. Aziz and M. S. Yusoff, Waste Manage., 2010, 30, 2113-2121.

14 E. Alfaya, O. Iglesias, M. Pazos and A. Sanromán, RSC Adv., 2015, 5, 14416-14424.

15 O. Iglesias, J. Gómez, M. Pazos and M. A. Sanromán, Appl. Catal., B, 2013, 144, 416-424.

16 A. Asghar, A. A. Abdul Raman and W. M. A. Wan Daud, J. Cleaner Prod., 2014, 87, 826-838.

17 X. Zhang, Y. Chen, N. Zhao, H. Liu and Y. Wei, RSC Adv., 2014, 4, 21575-21583.

18 P. V. Nidheesh, R. Gandhimathi, S. Velmathi and N. S. Sanjini, RSC Adv., 2014, 4, 5698-5708.

19 J. P. Guin, D. B. Naik, Y. K. Bhardwaj and L. Varshney, RSC Adv., 2014, 4, 39941-39947.

20 A. El-Ghenymy, R. M. Rodríguez, C. Arias, F. Centellas, J. A. Garrido, P. L. Cabot and E. Brillas, J. Electroanal. Chem., 2013, 701, 7-13.

21 N. Borrás, C. Arias, R. Oliver and E. Brillas, J. Electroanal. Chem., 2013, 689, 158-167.

22 Y. Wang, H. Zhao, S. Chai, Y. Wang, G. Zhao and D. Li, Chem. Eng. J., 2013, 223, 524-535. 
23 Y. Y. Chu, Y. Qian, W. J. Wang and X. L. Deng, J. Hazard. Mater., 2012, 199-200, 179-185.

24 O. García, E. Isarain-Chávez, A. El-Ghenymy, E. Brillas and J. M. Peralta-Hernández, J. Electroanal. Chem., 2014, 728, 1-9.

25 A. El-Ghenymy, C. Arias, P. L. Cabot, F. Centellas, J. A. Garrido, R. M. Rodríguez and E. Brillas, Chemosphere, 2012, 87, 1126-1133.

26 L. Feng, N. Oturan, E. D. van Hullebusch, G. Esposito and M. A. Oturan, Environ. Sci. Pollut. Res., 2014, 21, 8406-8416.

27 M. Panizza, E. Brillas and C. Comninellis, J. Environ. Eng. Manage., 2008, 18, 139-153.

28 B. P. Chaplin, Environ. Sci.: Processes Impacts, 2014, 16, 11821203.

29 W. Liu, Z. Ai and L. Zhang, J. Hazard. Mater., 2012, 243, 257264.

30 O. Iglesias, E. Rosales, M. Pazos and M. A. Sanromán, Environ. Sci. Pollut. Res., 2013, 20, 2252-2261.

31 K. Y. Foo and B. H. Hameed, J. Hazard. Mater., 2009, 171, 5460.

32 S. A. Messele, O. S. G. P. Soares, J. J. M. Órfão, C. Bengoa, F. Stüber, A. Fortuny, A. Fabregat and J. Font, Catal. Today, 2015, 240, 73-79.

33 C. Chen, H. Chen, X. Guo, S. Guo and G. Yan, J. Ind. Eng. Chem., 2014, 20, 2782-2791.

34 D. De Beer, J. F. Harbertson, P. A. Kilmartin, V. Roginsky, T. Barsukova, D. O. Adams and A. L. Waterhouse, Am. J. Enol. Vitic., 2004, 55, 389-400.

35 R. M. Sellers, Analyst, 1980, 105, 950-954.

36 K. Z. Elwakeel, G. O. El-Sayed and S. M. Abo El-Nassr, Desalin. Water Treat., 2014, DOI: 10.1080/ 19443994.2014.919606.
37 M. M. Rahman, M. Adil, A. M. Yusof, Y. B. Kamaruzzaman and R. H. Ansary, Materials, 2014, 7, 3634-3650.

38 M. E. Ossman, M. Abdel Fatah and N. A. Taha, Desalin. Water Treat., 2014, 52, 3159-3168.

39 A. Babuponnusami and K. Muthukumar, Chem. Eng. J., 2012, 183, 1-9.

40 A. Rey, J. A. Zazo, J. A. Casas, A. Bahamonde and J. J. Rodriguez, Appl. Catal., A, 2011, 402, 146-155.

41 M. S. Lucas and J. A. Peres, J. Hazard. Mater., 2009, 168, 1253-1259.

42 Y. Chu, D. Zhang, L. Liu, Y. Qian and L. Li, J. Hazard. Mater., 2013, 252-253, 306-312.

43 V. K. Gupta, B. Gupta, A. Rastogi, S. Agarwal and A. Nayak, J. Hazard. Mater., 2011, 186, 891-901.

44 V. K. Gupta, B. Gupta, A. Rastogi, S. Agarwal and A. Nayak, Water Res., 2011, 45, 4047-4055.

45 G. Busca, S. Berardinelli, C. Resini and L. Arrighi, J. Hazard. Mater., 2008, 160, 265-288.

46 E. Rosales, O. Iglesias, M. Pazos and M. A. Sanromán, J. Hazard. Mater., 2012, 213-214, 369-377.

47 E. Isarain-Chávez, C. De La Rosa, L. A. Godínez, E. Brillas and J. M. Peralta-Hernández, J. Electroanal. Chem., 2014, 713, 62-69.

48 P. Liu, S. He, H. Wei, J. Wang and C. Sun, Ind. Eng. Chem. Res., 2015, 54, 130-136.

49 Y. Ni, L. Wang and S. Kokot, Anal. Chim. Acta, 2000, 412, 185193.

50 N. Izaoumen, N. B. Abderrazik, K. R. Temsamani, S. Esplugas and E. Brillas, Afinidad, 2006, 63, 449-453. 